\title{
ESKİ ANADOLU TÜRKÇESİ ÜZERINDEKİ ÇALIŞMALARIN BUGÜNKÜ DURUMU VE KARŞILAŞTIĞI SORUNLAR
}

\author{
ZEYNEP KORKMAZ
}

1. § Eski Anadolu Türkçesi deyimi ile, Anadolu'da kurulan Türk yazı dilinin XII. yüzyıldan XV. yüzyıl ortalarına, yâni klâsik Osmanlıca'nın başlangıcına kadar uzanan dönemini kastediyoruz. Bu dönem, Oğuz - Türkmen lehçesinin, ilk defa sistemli olarak bir yazı diline dönüştügü dönemdir. Bundan dolayı Eski Anadolu Türkçesi'nin Türk dili tarihinde kendine has ayrı bir yeri vardır.

Türkolojinin oldukça yeni bir bilim dalı olması, Türk dilinin öteki alanları gibi, bu alandaki çalışmaları da geç başlatmıştır. Illk denemeleri geçen yüzyılın sonlarında Wickerhäuser, Salemann, Smirnoff, Vambéry gibi Batılı araştırıcılarla başlayan Eski Anadolu dil ve edebiyatı üzerindeki çalışmalar, bu yüzyılın ilk çeyreğinden sonra, Fuad Köprülü’nün öncülüğünde büyük aşamalar kaydetmiştir. Köprülü’den sonra sürdürülegelen yeni araştırmalarla Eski Anadolu Türkçesi'nin kuruluş ve gelişme dönemleri birçok yönleri ile aydınlığa kavuşturulmuştur denebilir. Bugün elimizde bu döneme ait manzum, mensur, dinî, lâdinî, edebî, felsefî tıbbî, tarihî, ahlâkî, destanî v.b. nitelikte yı̆ı̆ılarca metin malzemesi vardır. Dönemi temsîl eden edebî şahsiyetler ve bunlara ait eserler büyük ölçüde ortaya konmuştur. Eldeki malzemenin bir kısmu ya yalnız kaynak metin malzemesi olarak yayınlanmış yahut da dil ve edebiyat bakımlarından işlenip değerlendirilmiştir. Meveut malzemeye dayanılarak Eski Anadolu Türkçesi'nin dil yapısı da genel çizgileri ile ortaya konmuştur denebilir. Öyle ki, Anadolu'nun XII-XV. yüzylllar arasındaki siyasal, sosyal ve kültürel değişmelerine ve dil tarihindeki gelişmelere paralel olarak, bu dönemin dil yapısını, ayrıntılara giren bazı özellikleri dolayısiyle kendi arasında "Selçuklular dönemi Türkçesi" ve "Beylikler dönemi Türkçesi” olarak iki ayrı alt bölüme ayrma imkânı da olmuş-

* Bu yazının aslı 24-26 Eylül 1974 tarihleri arasında Napoli'de toplanmış olan Osmanlı ve Osmanlı Öncesi Araştırmaları seminerine bildiri olarak sunulmuştur. 
tur. Böylece, Eski Anadolu Türkçesi üzerindeki çalışmaların son 50 yıl içinde ulaşmış olduğu merhale oldukça sevinçiricidir.

Ancak, filoloji çalışmaları ve dil tarihi açısından konunun ayrıntılarına girildikçe, daha araştırıcıların önünde önemli işlerin ve çözüm bekleyen nice nice sorunların bulunduğu da gözden kaçmamaktadır. Aşağıda, Eski Anadolu Türkçesi üzerindeki çalışmaların bugünkü durumunu özetlerken, dolayısiyle bu sorunlara da temas etmeğe çalışacağız.

\section{Eski Anadolu Türkçesinin Kaynak Metin Durumu}

2. § Bugün elimizde Eski Anadolu Türkçesi alanına giren oldukça bol malzeme vardır. Yukarıda belirttiğimiz üzere, bu malzeme konu bakmından da pek çeşitlidir. Anadolu Türkçesi'nin kuruluş şartlarnna uygun olarak telif eserler yanında çeviri eserler de geniş bir yer tutar. Yalnız, kaynak metin malzemesi yüzyıllara göre ayrıldığında, bunların genellikle XIV. ve XV. yüzyıllarda yoğunlaştığı görülür. XIV. yüzyıldan gerilere doğru uzandıkça metinler azalmakta ve seyrekleşmektedir. Bu durum aşağıda ayrıca belirteceğimiz özel sebepler dışında, bir dereceye kadar da başlangı̧̣ dönemire ait bazı eserlerin kaybolmuş veya daha ele gę̧memiş olmaları ile ilgilidir.

Gerçekten de, bugün için daha Eski Anadolu Türkçesi'nin kuruluş dönemine giren eserlerinden birkısmmı bilemiyoruz. Eski kaynaklardan adların öğrendiğimiz bazı eserler ise ortada yoktur. Bunlardan elimizde olanlar da, dil bakımından yenileştirilmiş daha sonraki yüzyıllara ait yazma nüshalardur. Salsal-nâme, Şeyh San'an Hikâyesi, Gülşehrî'nin Kudûrî Tercümesi, Dânişmend-nâme, Battal-nâme ${ }^{1}$ gibi. Buna karşılık, son yıllarda yer yer kaynaklarda adına rastlanan veya rastlanmayan yeni bazı eserler ortaya çıkmış-

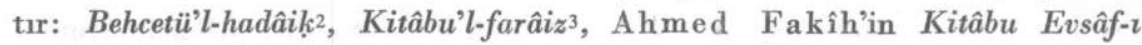
Mesâcidi'ş-Şerîfe'si ${ }^{4}$, Âşık Paşa'nun Fakr-nâme ve Vasf-ı hâl mesnevîleri ile Hikâye ve Kimyâ Risâle'leri', Ahmedî'nin Mirkaat-ı Edeb'i ${ }^{6}$ gibi.

1 Bu eserler icin bkz. F. Köprülü, Anadoluda Türk Dili ve Edebiyatının Tekâmülü̈ne Umumî bir Bakış, Yeni Türk Mecm. S. 4 (1933), s. 279;I. Mélik off, La Geste de Melik Dānişmend, Tome I, II, Paris 1960; Z. Korkmaz, Sadrü'd-din Şeyhoğlu, Marzubān-ıāme Tercümesi, Ank. UUniv. DTCF. yayım 1973, s. 58.

2 Bu eser üzerindeki yayın ve çalş̧malar için bkz. Z. Korkmaz not I'de göst. e., s. 58

3 Bkz. Z. Korkmaz, not l'de göst. e., s. 24 ve E. Blochet, Catalogue des Manuscrits Turc, Tome I, Paris 1932, s. 24, s. 62 ,

4. Bkz. H. Mazıoğlu, Ahmed Fakih, Kitäbu Evsäf-ı Mesācidi' serīfe, Ankara TDK. 1974.

5 Bkz. Agah Sirrı Levend, Assık Pasanın Bilinmeyen Iki Mesnevîsi: Fakr-nâme ve Vassf-ı Hâl, TDAY. 1953, s. 205-225; Âşšl Paşanın Bilinmeyen İki Mesnevîsi Daha: Hikâye ve Kimyâ Risâlesi, TDAY. 1954, s. 265-276.

6 Bkz. A. Alparslan, Ahmedinin Yeni Bulunan Bir Eseri, Mirkat-ı Edeb, TDED. X (1960), s. 35-40. 
İşte son 20-25 yllık araştırmaların yeni birtakım eserler daha ortaya koymuş olması, bu alandaki metin ve eser boşluklarının doldurulabilmesi için, bundan böyle de araştırmalara hızla devam edilmesi gereğini ortaya koymaktadır.

\section{Yazmalar Bibliyografyasmm Hazirlanması}

3. § Şimdiye kadar, bilinen yazma eserlerin kataloglanması bakımından ileri adımlar atılmış olmasına rağmen, metin kaynaklarının bütünü ile ortaya çıkmasını sağlayacak katalog çalışmaları tamamlanmıştır denemez. Daha kataloğu yapılmamış kitaplar ve kütüphâneler bulunduğu gibi, meveut katalogların bu yönden yetersiz sayılan yanları da vardır. Bazan, katalogda gördüğümüz bir eseri ararken, çok defa başka bir eserle karşılaştığımız olmaktadır. Zaman zaman da, yazmalar üzerinde incelemeler yapıldıkça, eski kataloglarda verilen bilgileri düzeltme gereği ortaya çıkmaktadır. Ayrıca, özel kitaphklarda bulunan yazmalar hakkındaki bilgilerimiz de yeterli değildir. Bu durumlar gösteriyor ki, Eski Anadolu Türkęesinin metin kaynaklan bakımından bugün için daha bütün eksikleri tamamlanmış bir bibliyografyasına sahip değiliz. Bu konuda gerek yazma eserler üzerinde çahşan katalog uzmanlarına gerek Eski Anadolu Türkçesi üzerinde çalş̧anlara düşen ortak görev, Türkiye ve Avrupa kitaplıklarının şimdiye kadar kataloglanmamış eserleriyle bibliyografik kaynaklarını da gözden geçirerek ve dağınık çalışmaları biraraya toplayarak, Eski Anadolu Türkçesi için güvenilir bir 'yazma eserler bibliyografyası' hazırlayabilmektir. Hele bazı mensur eserlerin, ayrı bölgelerde ve müteakıp yüzyllarda yapılan kopyalarla dil ve muhteva değişikliğine uğraması, kimi zaman da kopyalar sırasında eser adlarının bile değiştirilmiş olması, yazma eserlere dayanan bibliyografya çalışmalarını daha da gerekli kılmaktadır.

\section{Kaynak Metin Yaymı}

4. § 70-80 yıldır süregelen çalı̧̧alar sonunda, Eski Anadolu Türkçesi'nin metin kaynaklarından birkısmı metin yayın veya kritik metin yayını olarak ilim alanına sunulabilmiştir. Sultan Veled'in Türkçe şiirleri, Ahmed Fakîh'in Çarhnâme'si ile Kitâbu Evsâf-ı Mesâcidü'ş-Şerîfe'si, Şeyyad Hamza'nın şiirleri, Melik Dânişmend Gâzî adına yazılan Dânîşmend-nâme, Yunus Emre Dîvânt, Âşık Paşa'nın birkısım şïleri, Şe yhoğlu'nun Marzubân-nâme'si, Dede Korkut Hikâyeleri, Şeyh î̀nin Husrev ii 
Şîrin'i, Süleyman Çelebî'nin Mevlid'i, Mehmed'in Işshâme'si, Ebulleys Semerkandt'den yaplan Tezkiretü'l-Evliyâ Tercümesi, Neşrî'nin Kitâb- $\imath$ Cihannümâ'sı, Bergamalı Kadrî'nin Müyessiretü'l-ulûm'ı bu türden yayinlardir7.

Bu yayınlara, herhangi bir, eserden kısmen yapılmış olan metin yayınlarını da ekleyebiliriz: Behcetül-hâdâik fî Mev'izeti'l-halâik'tan derlenmiş koşuklar ${ }^{8}$, Dursun Fakîh'in Gazavat-nâme'si', Kul Mes' ûd'un Kelîle Dimne Tercümesi, Dâsitân-ı Muhammed Hanefî ve Mihr $\ddot{u}$ Vefâ'dan aktarılan parçalar ${ }^{10}$, Düstur-nâme-i Enverî'nin Umur Paşa Bölümü̈11, Şeyhî'nin Harnâme'sinden ${ }^{12}$ yapılan yayınlar da kısmî metin yayınlarıdır. Bütün bu yayınlar ile Eski Anadolu Türkçesi üzerindeki inceleme ve araştırmalar geniş imkânlar kazanmış bulunmaktadır. Ancak, metin yayını konusunda, önümüzde daha aşılacak büyük mesafelerin bulunduğunu da unutmamak gerekir.

Eldeki metinlerden birkısmı bugün için daha yalnız fotokopi veya arap harfleri ile yapılıış yayınlar durumundadır. Bunlar kritik metin yayını durumuna getirilememişlerdir. Behcetü'l-hadâik, Şeyyad Hamza'nın Yûsuf ve Züleyhâ'sı, Gülşehrî'nin Mantıku't-tayr'ı, Kadı Burhâneddin ve Şeyhî dîvanları, Hoca Mes'ûd'un Süheyl ü Nevbahâr'1, Ferhenk-nâme-i Sa'dî Tercümesi, Kırk Vezîr Hikâyeleri, Dâsitân-ı Ahmet Harâmî gibi. Gerçi bu nitelikteki eserlerden bazları Türkiye ve Avrupa üniversitelerinin Türk Dili ve Edebiyatı bölümlerinde lisans, doktora ve doçenlik tezleri olarak ele alınıp işlenerek kritik metinler durumuna getirilmiş iseler de, yayın alanına çıkmamış olduklarından, yararlanma bakımından yazma eserlerden farkları yok gibidir.

Hiç şüphe yok ki, Türkiye ve Avrupa kitaplıklarında bulunan kaynak metinlerin pek çoğu da daha yayın için el atılmamış durumdadır. Ali'nin Kıssa-i Yûsuf'u, Süle Fakih'in Yûsuf ve Züleyhâ'sı, Erzurumlu Darîr'in bütün eserleri, Ahmedî'nin İskender-nâme'si, Âşık Paşa'nun Garip-nâme'si ve daha

$7 \mathrm{Bu}$ yaymlarn tam künyesi için bkz. Z. Korkmaz, Marzubānnāme Tercümesi yaymu, s. $59-66$.

8 S. Buluç, TDAY. 1963 (Ankara 1964), s. 161-201.

9 S. Bulu ç, X. Türk Dil Kurultayında Okunan Bilimsel Bildiriler, 1963, (Ankara 1964), s. 11-22.

10 Z. Korkmaz, Eski Anadolu Türkçesinin Îki Ürünü ve Yazarları Üzerine, XI. Türk Dil Kurultaymda Okunan Bilimsel Bildiriler, 1966 (Ankara 1968), s. 17-27.

11 I. Mélik off (Sayar), Le Destan d'Umur Pacha, Paris 1954.

12 F. Demirtaş (Timurtaş), Harnâme, TDED III/3-4 (1949), s. 369-387; Şeyhî, HayatıEserleri-Eserlerinden Seçmeler, İst. Üniv. Edeb. Fak. yaymu, İstanbul 1968. 
niceleri.. Bu kadar zengin bir dil malzemesinin bulunduğu bir dönemin bütün metinlerini yayın alanına çıkarabilmek elbette pek güç bir iştir. Hele eserlerden birkısmının pek hacimli olması ve bunların ayrı bölgelerde ve ayrı devirlerde yapılmış pek çok elyazmalarının bulunması, kritik metin yayınları üzerindeki çalışmaları oldukça güçleştirmekte ve kaynak metinlerin kritik yayına hazırlanmasını, el atılması güç birer iş durumuna sokmaktadır. Yalnız şurası da bir gerçektir ki, Eski Anadolu Türkçesi ile ilgili çeşitli dil ve edebiyat konularında yapılan araştırmalarda başarılı sonuçların alınabilmesi de öncelikle bol kaynak metin yayınlarının gerçekleştirilebilmesine bağlıdır. $\mathrm{Bu}$ alandaki boşluklar, bazı önemli konularda, beklenen verimli sonuçlara ulaşılmasını elbette engellemektedir. $\mathrm{O}$ halde, bu alanın yetkililerine düşen önemli bir görev de, kaynak metin yayınları bakımından bir organizasyon ve plânlamaya gitmektedir. Böylece Eski Anadolu Türkçesi'nin kaynak metinleri daha düzenli bir biçimde ele alınmış ve ortaya konmuş olacaktır.

\section{Inceleme ve Araştırmalar}

5. § Eski Anadolu Türkçesi ile ilgili inceleme ve araştırmalara gelince: 70-80 yillık çalışmalarla bu alanda da epey verimli sonuçlar alınmıştır. Bir yandan XIII.-XV. yüzyıllara ait birkısım metinlerin yayın alanına çıkması, bir yandan da belirli metinlere dayalı dil inceleme ve araştırmalarının yapılmış olması, Eski Anadolu Türkçesi'nin dil yapısını ana çizgileri ile ortaya koymuştur. Hele, kritik metin yayınlarının güçlüğü dolayısiyle metin yayını yapılamayan bazı eserler için doğrudan doğruya bunların güvenilir yazmalarına dayanılarak dil incelemelerine gidilmiş olması, münferit eserler yolu ile Eski Anadolu Türkçesi'nin dil yapısına daha kestirmeden hizmet eden çalışmalardır. Ali'nin Kıssa-i Yûsuf'unun, Behcetü'l-hadâik'ın, Sultan Veled'in, Garip-nâme'nin, Kelîle ve Dimne'nin, Kadı Burhâneddin Dîvânı'nın, Marzubânnâme'nin, Kusasü'l-enbiyâ Tercümesi'nin, Cerrâhiye-i İlhâniye'nin, Kırk Vezîr Hikâyeleri ile Şeyhî ve çağdaşlarmın dilleri bu yoldaki çalışmalarla ${ }^{13}$ ortaya konabilmiştir. Bunlar dışında, belirli gramer konularını inceleyen bazı araşturmalar da yapılmıştır. Vasıta hâli ekini (instrumentalis) ve fiil müştaklarını (verbalnomina ve verbaladverbia) ele alan çalışmalar ${ }^{14}$ gibi. Bunlara, yu-

$13 \mathrm{Bu}$ çalışmaların bibliyografik künyeleri için bkz. Z. Korkmaz, Marzubān-nāme Tercümesi yayın, s. 58-66.

14 Bkz. S. Çăğatay, Uygurca ve Eski Osmanlıcada Instrumental - n, DTCF. Derg. 1/3 (1943), s. 93-107; Eski Osmanlvada Fiil Müsstaklart, DTCF. Derg. V/4 (1947), s. 353-368, V/5 (1947), s. $525-552$, VI/1-2 (1948), s. 27-47. 
karıda kaynak metinler dolayısiyle belirttiğimiz gibi, bazı edebî şahsiyetlerin yeni eserlerini ortaya çıaran araştırmaları da katabiliriz: Behcetü'l-hadâik'ı ilim alanına tanıtan ilk yaz1 ${ }^{15}$, Ahmed Fakłîh'in Kitâbu Evsâf-ı Mesâcidi'şşerîfe'sini ${ }^{16}$, Â şık Paşa'nın Fakr-nâme ve Vasf-ı hâl'i ile, Hikâye ve Kimyâ risâlelerini, A h medî’nin Mirkaadü'l-edeb sözlüğünü tanitan incelemeler ${ }^{17}$, Kaabus-nâme ve Marzubân-nâme Tercümeleri'nin Şeyhoğlu'na aidiyetini ortaya koyan çalışmalar ${ }^{18}$, bu türün örnekleridir. Bunlara, Türk dili alanının tümünü kapsayan bazi araştırmaların dolayısiyle Eski Anadolu Türkçesi'ni ele alan bölümlerini de katabiliriz ${ }^{19}$. Yayınlanmış çeşitli metinlere ve yapılan araştırmalara dayanılarak Eski Anadolu Türkçesi'nin gramer yapısını genel çizgileri ile ortaya koyan bir makale de yayınlanmıştır ${ }^{20}$.

Ayrıca, bu dönemin söz hazinesini meydana çıkaran değerli çalışmalar da yapılmış ve yapılagelmektedir. Ankara'da Türk Dil Kurumu'nca gerçekleştirilen XIII. Yüzyıldan Günümüze Kadar Tanıkları ile Tarama Sözlüğ̈̈i adlı eser ile, onun yeniden ele alınan Tarama Sözlü̆̆̈̈ adlı ikinci serisi, özel çalışmalarla gerçekleştirilmesi pek güç olan ve yüzlerce kaynağın taranmasına dayanan başarılı bir hizmettir ${ }^{21}$. Bu hizmete, birkaç yıl önce hazırlığına başlanan ve hâlen çalışmaları süregelen Anadolu bölgesinin Tarihsel Türk Dili Sözlüğü'nü de katabiliriz.

Bütün bu verimli çalışmalara rağmen, bugün için Eski Anadolu Türkçesi'nin çözüm bekleyen daha pek çok sorunlarının bulunduğunu da inkâr edemeyiz. Herhangi bir bölge ve ana dönem için filoloji çalışmalarından beklenen amacı gözönünde bulundurarak, ileriki inceleme ve araştırmalarla ilgili sorunları şu ana noktalarda toplayabiliriz:

15 Bkz. I. H. Ertaylan, VII. H./XIII. M. Asra Ait Çok Değerli Bir Türk Dili Yadigârı: Behcetü'l-hadāik fi mev'izeti'l-haläilk TDED. III/3-4 (Istanbul 1949), s. 275-293.

16 H. Mazıoğlu, Anadoluda XIII. Yüzyll Ürünlerinden Bir Eser, X. Türk Dil Kurultayinda Okunan Nilimsel Bildiriler 1963 (Ankara 1964), s. 75-79.

17 Bkz. not 5 ve 6'da göst. yazılar.

18 Z. Korkmaz, Kabus-nāme de Marzuban-nāme Çevirileri Kimindir? TDAY. 1966, (Ankara 1967), s. 267-275; Wer ist der Übersetzer des Käbus-näme und Marzubān-nāme, Studia Turcica, Budapest 1971, s. 259-266.

19 Bkz. Z. Korkmaz, Türk Dilinde + ça/+şe eșitlik hâli (äquativus) eki ve bu ekle yapulan isim teşkilleri üzerine bir deneme, DTCF. XVII/3-4 (Ankara 1960), s. 275-358.

20 Bkz. M. Mansuroğlu, Das Altosmanische, Philogiae Turcicae Fundamenta I, Wiesbaden 1959 , S. 160-182.

21 XIII. Yüzyzldan Günümüze Kadar Tanıkları İle Tarama Sözlüğü I-IV, I. basım TDK. Ankara 1947-1957, 2. basım: XIII. Yüzyzldan Beri Türkiye Türkçesi Ile Yazılmış Kitaplardan Toplanan Tanılariyle TARAMA SÖZLÜĞÜ, I-VII, Ankara 1963-1974. 
1. Dil bakımından öncelikle üzerinde durulması gereken ve henüz yayın alanına çıkmamış olan önemli eserleri, kritik metin yayını, dil incelemesi, sözlük ve indekslerinin hazırlanması ile ortaya koyacak müstakil monografilere hız verilmesi. Yukarıda belirttiğimiz üzere birkısım Eski Anadolu eserlerinin, elde epey yazma nüshalarının bulunması, bunların kısmen daha sonraki istinsahlar ile dil bakımından azçok bozulmuş ve yenileştirilmiş olmaları, hele mensur eserlerdeki dil bozulmasının aynı eserin değişik nüshalarını müstakil birer eser sayduracak kadar ileri gidişi, kritik metin yayınları ile buna dayalı monografileri kaçınılmaz çalışmalar durumuna getirmektedir.

2. Eldeki metinlere ve monografilere göre her yüzyılın genel dil tablosunun bütün ayrıntıları ile çizilmesi. Bu yolla yüzyıllar arasında değişen gelişme şartları daha yakından izlenebilecektir.

3. Eski Anadolu Türkçesi'nin dil yapısını aydınlatma bakımından özel önem taşıyan bazı konuların ayrıca ele alınarak işlenmesi. Bir örnek vermek gerekirse, Eski Anadolu Türkçesi'nin imlâsını gösterebiliriz. Bu konu, bazı eserlerin imlâları üzerinde ayrı ayrı durulmuş olmasına rağmen, daha bütün yönleri ile aydınlanabilmiş değildir. Genellikle Eski Anadolu Türkçesi'nde de Osmanlıca'da olduğu gibi, klişeleşmiş bir imlâdan söz edilmektedir. Oysa, son yıllarda bazı eserler üzerinde yapılan araştırmalar, XII.-XV. yüzyıllar arasındaki imlânın henüz klişeleşmemiş olduğuna, Arap yazısının müsaadęi oranında azçok fonetik imlâ olma özelliği de taşıdığına işâret etmektedir. Vokalizasyon için hareke sisteminin yer almış olması ( (

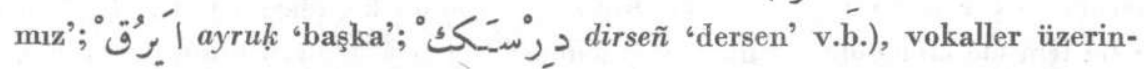
deki uzunlukları belirtmek üzere, Arapça ve Farsça kelimelerde olduğu gibi Türkçe kelimelerde de ayrica elif (l), vav (و) ve ye(ى) harfleriyle, met (T)

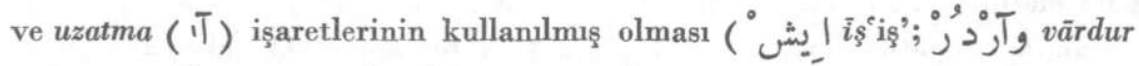

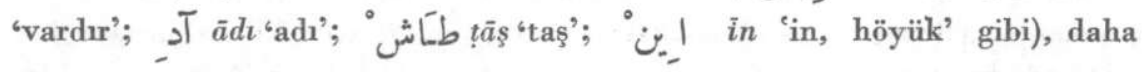
sonraki klâsik imlâda ayrı yazılan bazı şekillerin burada bitişik olarak yazılması ve özellikle müstakil kelimeler arasındaki telâffuzu esas alan liyezonların yazıda da hareke ve bitiştirmelerle belli edilmesi

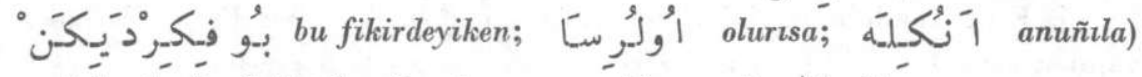
ve daha baş̧ka belirtiler, bu durumu açıklayan örneklerdir.

Bizce, Eski Anadolu Türkçesi'nin imlâsı üzerinde yapılacak bütün bir dönemi içine alan derinlemesine bir inceleme, yalnız imlâ konusundaki bil- 
gilerimizi ilerletmekle kalmayacak, daha başka konuların aydınlanmasına da yardımcı olacaktır. Oğuzca, XIII. yüzyıl Anadolu'sunda konuşma dilinden yazı diline geçme mücadelesi vermiş olduğundan ve XIII.-XV. yüzyıllar arasında daha konuşma dilinđen yeterince ayrılmış klâsik bir yazı dili teşekkül etmemiş olduğundan, bu konunun işlenmesi dolayısiyle, ogünün konuşma dili ile yazı dili arasındaki karşılıklı bağlantı ve ilişkileri de ortaya koyacak; Eski Anadolu Türkçesi'nin fonolojik ve fonetik yapısı üzerinde daha kesin yargılara ulaşma imkânını doğuracaktır. Ayrıca, bu yolla o dönem Anadolu Türkçesindeki ağız ayrılıkları ve bölgeleri biribirinden ayıran kriterler de tesbit edilebileceği için, klâsik Osmanlıca'nın kuruluşundan önceki dönemle bugünkü Anadolu ağızları arasında kurmağa çalıştığımız köprü de daha sağlam temelmellere dayandurılmış olacaktır. Bu türlü araştırmalardan elde edilecek sonuçlar, daha sonraki bir merhalede, Anadolu bölgesindeki ağız ayrılıkları ile Oğuzların çeşitli kolları arasındaki bağlantıların kurulmasına da büyük yardımeı olacaktır kanısındayız.

Görülüyor ki, birtakım önemli sonuçlara ulaşılabilmesi için, Eski Anadolu Türkçesi'nin imlâsından başlayarak fonoloji v.b. konularının birer bütün olarak ele alınıp değerlendirilmesi gerekmektedir.

4. Yukarıda ileri sürdüğümüz hususları, dönemin morfolojisi ve ek türleri için de ileri sürebiliriz. Şimdiye kadar genellikle münferit eserler ele alınmış, bu eserlerin özel dil yapılarını ortaya koyabilmek için, morfolojilerine de yer verilmiştir. Ancak, elimizde morfoloji konularını bütün bir dönem için ele almış olan makale ve monografiler pek azdır. Bunun da başlıca sebebi, şimdiye kadar herbir eseri yayın alanına çıkaran müstakil monografilerin azlığıdır. Bir dönemin çeşitli yönleri ile aydınlanabilmesi için, aradaki metin ve malzeme boşluklarının doğrudan doğruya yazma eserlere başvurularak kapatılabilmesinden doğan güçlük, bu konudaki çalışmaları ister istemez engellemiş ve geciktirmiştir. Ancak, bugün artık elimizde daha bol metin malzemesi ve münferit eser incelemeleri bulunduğuna göre, morfolojinin şeşitli konuları için bütünlemesine araştırmalara girişilebileceği görüşündeyiz.

5. Eski Anadolu metinlerinin sentaks yapısı, Arap ve Fars dillerinden yapılan çevirilerin dilin çatısı üzerindeki etkileri ve telif eserlerle çeviri eserler arasındaki sentaks farkları bugün önümüzde hâlâ el atılmamış sorunlar olarak durmaktadır. Bu sorunların çözümü ise, telif ve çeviri eserler üzerinde yapılacak yeni araştırmalara bağlıdır. 
6 Eski Anadolu Türkçesinin semantik alanına giren anlam olayları ve stilistik yönü de bugüne kadar hiç el sürülmemiş konular durumundadur. Şimdiye kadar çeşitli eserlerin dil yapıları incelenirken, dolayısiyle yapılmı ş olan bazı açıklamalar yeterli olmaktan uzak durumdadır. Artık bundan sonra bu konulara da el atılmasının sırası çoktan gelmiş bulunmaktadır. Anlam olayları ile ilgili olarak, ayrıca, XII.-XV. yüzyıllar arsındaki çeşitli kültür alı̧̧verişlerinin Eski Anadolu Türkçesi üzerindeki etki ve kalıntılarının da ortaya konması gerekmektedir.

Yukanda belirtmeğe çalıştığımız önemli sebepler dolayısiyle, Eski Anadolu Türkçesi'nin genel dil yapısını ortaya koyan toplayıcı çalışmalar ne yazık ki, daha bir makale ölçüsünü aşamamıştır. Bugüne kadar bu dönemi çeşitli metinler asasında ayrıntıları ile ele alabilmiş bir Eski Anadolu Türkçesi gramerinin yazılamamış olması, yukarıda belirttiğimiz sorunların programlı bir şekilde ele alınması gereğine bir kere daha işaret etmektedir.

8. Bu dönemle ilgili diğer bir önemli sorun da şudur:

XIII. yüzylın 2. yarısından XV yüzyıl ortalarına kadar uzanan dönem genel çizgileri ile bilindiği halde, XII. yüzyıl başından XIII. yüzyıl ortalarına kadar uzanan ve Eski Anadolu Türkçesi'nin "karanlı dönemi" veya "sisli dönemi" diye adlandırılan başlangı̧ dönemi yeterince aydınhı̆a kavuşturulamamıştır. Bunun başlıca sebebi, bu dönemin kaynak eserler bakımından yeterince dolgun olmamasıdır. Son 15-20 yıl öncesine kadar Anadolu Türkçesi'nin kuruluş şartları bakımından Orta-Asya ile bağlantılı bulunmadığı ve 0 ğ u zca'nın Anadolu'da Arapça ve Farsça ile çarpışa çarpışa ancak XIII. yüzyılın ikinci yarısından sonra bir yazı dili durumuna gelebildiği görüşü hâkim idi. Behcetü'l-hadâik ve Kudurî Tercümesi, Kitâbu'l-farâiz gibi dil bakımından, Anadolu'daki Oğuz yazı dili ile Orta-Asya yazı dili arasında karışı bir dil yapısına sahip bazı eserlerin ortaya çıkışı, son ylllarda dikkat ve incelemeleri karışık dilli eserlerle, Oğuzca'nın XI.-XIII. yüzyıllar arasındaki durumuna yöneltmiştir. Bu konuda şimdiye kadat yapılan araştırma sonuçları, Eski Anadolu Türkçesi'nin başlangıç dönemi ile Orta-Asya yazı dili arasında normal bir bağlantının bulunduğu, Eski Anadolu Türkçesi'nin sanıldığından daha gerilere, hiç olmazsa XII. yüzyıl ortalarına kadar götürülebileceği, Oğuzca'nın Anadolu bölgesinde müstakil bir yazı dili olabilmek için yalnız Arapça ve Farsçaya karşı değil, XII. yüzyılın 2. yarısından buyana, Anadolu'daki kısmen eski Türk yazı dili özelliklerini taşıyan karışık dile karşı da bir savaş vermek zorunda kaldığı görüşüne uzanabilmiştir. Ancak şu var ki, Ali’nin Kıssa-i 
Yûsuf'u, Behcetü'l-hadâik ve Kudûrî Tercümesi gibi eserlerin hangi bölgelerde, hangi tariblerde veya kimler tarafindan yazıldıklan bilinemediği, Anadolu bölgesinde yazıldığı bilinen Salsal-nâme, Dânişmend-nâme, Battal-nâme gibi ilk dönem eserleri de ya elde bulunmadığı ya da elde bunların ancak dil bakımından yenileştirilmiş nüshaları bulunduğu için, bu dönem üzerindeki sis perdesi bugün için tam olarak sıyrılmıştır denemez. Bu konudaki sonuçlara yalnız ihtiyat kaydı ve istidlâller yolu ile varabiliyoruz. Bugün bu dönem üzerinde çalışan araştırıcılara düşen bir diğer önemli görev, bu konuyu gereğince aydınlatabilecek araştırmalara yönelmektir. Bunun için de, kitaplıklardaki karışık dilli eserlerin bu açıdan ve yeni baştan incelenip değerlendirilmeleri gerekmektedir. Ayrıca, Oğuzca, Kaşgarlı Mahmud'un bıraktığı noktadan yeniden ele alınarak, XI.-XIII. yüzyllar arasındaki dönemi, hem Anadolu bölgesini hem de Anadolu bölgesine $O$ ğuz etnolojisi bakımından kaynaklık eden Horasan ve Harezm bölgelerini de içine alacak biçimde araştırılmalıdır. Eski Anadolu Türkçesi'nin başlangı̣ dönemini örten sis perdesi, ancak bu yönde yapılacak daha başka yeni araştırmalarla kalkabilecektir. Bu araştırmalar sırasında yazılış alanları belli yeni eserlerin ele geçirilebilmesi, hiç şüphe yok ki problemin çözümüne en iyi ışı̆̆ tutmuş olacaktır.

Filoloji, dil özelliklerinden ve dil yapısından düşünce sistemine doğru uzanan bir kültür araştırması olduğuna göre, Anadolu bölgesinde yeni bir kuruluş halinde kendini gösteren 0 ğu z kültürünün bu eski dönemi ve Türk dili tarihindeki yeri de, ancak Eski Anadolu Türkçesi üzerinde yapılacak ayrıntılı ve sistemli yeni çalı̧̧malarla ortaya konabilecektir. 